\title{
On the Stability of an $m$-Variables Functional Equation in Random Normed Spaces via Fixed Point Method
}

\author{
A. Ebadian, ${ }^{1}$ M. Eshaghi Gordji, ${ }^{2}$ H. Khodaei, ${ }^{2}$ \\ R. Saadati, ${ }^{3}$ and Gh. Sadeghi ${ }^{4}$ \\ ${ }^{1}$ Department of Mathematics, Payame Noor University, Tehran, Iran \\ ${ }^{2}$ Department of Mathematics, Semnan University, P.O. Box 35195-363, Semnan, Iran \\ ${ }^{3}$ Department of Mathematics, Iran University of Science and Technology, Behshahr, Iran \\ ${ }^{4}$ Department of Mathematics and Computer Sciences, Tarbiat Moallem University Sabzevar, \\ Sabzevar, P.O. Box 397, Iran
}

Correspondence should be addressed to M. Eshaghi Gordji, madjid.eshaghi@gmail.com and R. Saadati, rsaadati@eml.cc

Received 17 September 2011; Revised 5 January 2012; Accepted 29 January 2012

Academic Editor: Seenith Sivasundaram

Copyright (C) 2012 A. Ebadian et al. This is an open access article distributed under the Creative Commons Attribution License, which permits unrestricted use, distribution, and reproduction in any medium, provided the original work is properly cited.

At first we find the solution of the functional equation $D_{f}\left(x_{1}, \ldots, x_{m}\right):=\sum_{k=2}^{m}\left(\sum_{i_{1}=2}^{k} \sum_{i_{2}=i_{1}+1}^{k+1} \ldots\right.$ $\left.\sum_{i_{m-k+1}=i_{m-k}+1}^{m}\right) f\left(\sum_{i=1, i \neq i_{1}, \ldots, i_{m-k+1}}^{m} x_{i}-\sum_{r=1}^{m-k+1} x_{i_{r}}\right)+f\left(\sum_{i=1}^{m} x_{i}\right)-2^{m-1} f\left(x_{1}\right)=0$, where $m \geq 2$ is an integer number. Then, we obtain the generalized Hyers-Ulam-Rassias stability in random normed spaces via the fixed point method for the above functional equation.

\section{Introduction and Preliminaries}

A basic question in the theory of functional equations is as follows: "when is it true that a function that approximately satisfies a functional equation must be close to an exact solution of the equation?"

If the problem accepts a solution, we say the equation is stable. The first stability problem concerning group homomorphisms was raised by Ulam [1] in 1940 and affirmatively solved by Hyers [2]. The result of Hyers was generalized by Aoki [3] for approximate additive function and by Rassias [4] for approximate linear functions by allowing the difference Cauchy equation $\|f(x+y)-f(x)-f(y)\|$ to be controlled by $\varepsilon\left(\|x\|^{p}+\|y\|^{p}\right)$. Taking into consideration a lot of influence of Ulam, Hyers, and Rassias on the development of stability 
problems of functional equations, the stability phenomenon that was proved by Rassias is called the Hyers-Ulam-Rassias stability. In 1994, a generalization of Rassias theorem was obtained by Găvruţa [5], who replaced $\varepsilon\left(\|x\|^{p}+\|y\|^{p}\right)$ by a general control function $\varphi(x, y)$ (see also [6-24]).

In the sequel we adopt the usual terminology, notations, and conventions of the theory of random normed spaces, as in [25-29]. Throughout this paper, let $\Delta^{+}$be the space of distribution functions, that is,

$$
\begin{aligned}
\Delta^{+}:= & \{F: \mathbb{R} \cup\{-\infty, \infty\} \longrightarrow[0,1]: F \text { is left-continuous } \\
& \text { nondecreasing on } \mathbb{R}, F(0)=0 \text { and } F(+\infty)=1\}
\end{aligned}
$$

and the subset $D^{+} \subseteq \Delta^{+}$is the set

$$
D^{+}=\left\{F \in \Delta^{+}: l^{-} F(+\infty)=1\right\},
$$

where $l^{-} f(x)$ denotes the left limit of function $f$ at the point $x$. The space $\Delta^{+}$is partially ordered by the usual pointwise ordering of functions, that is, $F \leq G$ if and only if $F(t) \leq G(t)$ for all $t \in \mathbb{R}$. The maximal element for $\Delta^{+}$in this order is the distribution function given by

$$
\varepsilon_{0}(t)= \begin{cases}0 & \text { if } t \leq 0 \\ 1 & \text { if } t>0\end{cases}
$$

Definition 1.1 (see [28]). A mapping $T:[0,1] \times[0,1] \rightarrow[0,1]$ is a continuous triangular norm (briefly, a $t$-norm) if $T$ satisfies the following conditions:

(a) $T$ is commutative and associative,

(b) $T$ is continuous,

(c) $T(a, 1)=a$ for all $a \in[0,1]$;

(d) $T(a, b) \leq T(c, d)$ whenever $a \leq c$ and $b \leq d$ for all $a, b, c, d \in[0,1]$.

Typical examples of continuous $t$-norms are $T_{P}(a, b)=a b, T_{M}(a, b)=\min (a, b)$, and $T_{L}(a, b)=\max (a+b-1,0)$ (the Łukasiewicz $t$-norm).

Recall (see $[30,31]$ ) that if $T$ is a $t$-norm and $\left\{x_{n}\right\}$ is a given sequence of numbers in $[0,1], T_{i=1}^{n} x_{i}$ is defined recurrently by

$$
T_{i=1}^{n} x_{i}= \begin{cases}x_{1} & \text { if } n=1 \\ T\left(T_{i=1}^{n-1} x_{i}, x_{n}\right) & \text { if } n \geq 2\end{cases}
$$

$T_{i=n}^{\infty} x_{i}$ is defined as $T_{i=1}^{\infty} x_{n+i}$.

It is known [31] that for the Łukasiewicz $t$-norm the following implication holds:

$$
\lim _{n \rightarrow \infty}\left(T_{L}\right)_{i=1}^{\infty} x_{n+i}=1 \Longleftrightarrow \sum_{n=1}^{\infty}\left(1-x_{n}\right)<\infty
$$


Definition 1.2 (see [29]). A random normed space (briefly, $\mathrm{RN}$ space) is a triple $(X, \Lambda, T)$, where $X$ is a vector space, $T$ is a continuous t-norm, and $\Lambda$ is a mapping from $X$ into $D^{+}$such that the following conditions hold:

(RN1) $\Lambda_{x}(t)=\varepsilon_{0}(t)$ for all $t>0$ if and only if $x=0$,

(RN2) $\Lambda_{\alpha x}(t)=\Lambda_{x}(t /|\alpha|)$ for all $x \in X, \alpha \neq 0$,

(RN3) $\Lambda_{x+y}(t+s) \geq T\left(\Lambda_{x}(t), \Lambda_{y}(s)\right)$ for all $x, y \in X$ and $t, s \geq 0$.

Definition 1.3. Let $(\mathrm{X}, \Lambda, \mathrm{T})$ be an $\mathrm{RN}$ space.

(1) A sequence $\left\{x_{n}\right\}$ in $X$ is said to be convergent to $x$ in $X$ if, for every $\epsilon>0$ and $\lambda>0$, there exists positive integer $N$ such that $\Lambda_{x_{n}-x}(\epsilon)>1-\lambda$ whenever $n \geq N$.

(2) A sequence $\left\{x_{n}\right\}$ in $X$ is called Cauchy if, for every $\epsilon>0$ and $\lambda>0$, there exists positive integer $N$ such that $\Lambda_{x_{n}-x_{m}}(\epsilon)>1-\lambda$ whenever $n \geq m \geq N$.

(3) An RN space $(X, \Lambda, T)$ is said to be complete if and only if every Cauchy sequence in $X$ is convergent to a point in $X$. A complete $R N$ space is said to be a random Banach space.

Theorem 1.4 (see [28]). If $(X, \Lambda, T)$ is an $R N$ space and $\left\{x_{n}\right\}$ is a sequence such that $x_{n} \rightarrow x$, then $\lim _{n \rightarrow \infty} \Lambda_{x_{n}}(t)=\Lambda_{x}(t)$ almost everywhere.

Theorem 1.5 (see $[32,33])$. Let $(S, d)$ be a complete generalized metric space, and let $J: S \rightarrow S$ be a strictly contractive mapping with Lipschitz constant $L<1$. Then, for each given element $x \in S$, either

$$
d\left(J^{n} x, J^{n+1} x\right)=\infty
$$

for all nonnegative integers $n$ or there exists a positive integer $n_{0}$ such that

(1) $d\left(J^{n} x, J^{n+1} x\right)<\infty$, for all $n \geq n_{0}$,

(2) the sequence $\left\{J^{n} x\right\}$ converges to a fixed point $y^{*}$ of $J$,

(3) $y^{*}$ is the unique fixed point of $J$ in the set $\Omega=\left\{y \in S \mid d\left(J^{n_{0}} x, y\right)<\infty\right\}$,

(4) $d\left(y, y^{*}\right) \leq(1 /(1-L)) d(y, J y)$ for all $y \in \Omega$.

The theory of random normed spaces (RN spaces) is important as a generalization of deterministic result of linear normed spaces and also in the study of random operator equations. The notion of an RN space corresponds to the situations when we do not know exactly the norm of point and we know only probabilities of possible values of this norm. The RN spaces may also provide us the appropriate tools to study the geometry of nuclear physics and have important application in quantum particle physics. The generalized HyersUlam stability of different functional equations in random normed spaces (RN spaces) and fuzzy normed spaces has been recently studied in, Alsina [34], Mirmostafaee et al. [35-38], Miheț and Radu [26, 27, 39, 40], Miheț et al. [41, 42], Baktash et al. [43] and Saadati et al. [44]. 
In this paper, we consider the $m$-dimensional additive functional equation

$$
\sum_{k=2}^{m}\left(\sum_{i_{1}=2}^{k} \sum_{i_{2}=i_{1}+1}^{k+1} \ldots \sum_{i_{m-k+1}=i_{m-k}+1}^{m}\right) f\left(\sum_{i=1, i \neq i_{1}, \ldots, i_{m-k+1}}^{m} x_{i}-\sum_{r=1}^{m-k+1} x_{i_{r}}\right)+f\left(\sum_{i=1}^{m} x_{i}\right)=2^{m-1} f\left(x_{1}\right),
$$

where $m \geq 2$ is an integer number. It is easy to see that the function $f(x)=a x$ is a solution of the functional equation (1.7).

As a special case, if $m=2$ in (1.7), then the functional equation (1.7) reduces to

$$
f\left(x_{1}+x_{2}\right)+f\left(x_{1}-x_{2}\right)=2 f\left(x_{1}\right) \text {. }
$$

Also by putting $m=3$ in (1.7), we obtain

$$
\sum_{i_{1}=2}^{2} \sum_{i_{2}=i_{1}+1}^{3} f\left(\sum_{i=1, i \neq i_{1}, i_{2}}^{3} x_{i}-\sum_{r=1}^{2} x_{i_{r}}\right)+\sum_{i_{1}=2}^{3} f\left(\sum_{i=1, i \neq i_{1}}^{3} x_{i}-x_{i_{1}}\right)+f\left(\sum_{i=1}^{3} x_{i}\right)=2^{2} f\left(x_{1}\right),
$$

that is,

$$
f\left(x_{1}-x_{2}-x_{3}\right)+f\left(x_{1}-x_{2}+x_{3}\right)+f\left(x_{1}+x_{2}-x_{3}\right)+f\left(x_{1}+x_{2}+x_{3}\right)=4 f\left(x_{1}\right) .
$$

The main purpose of this paper is to prove the stability of (1.7) in random normed spaces via the fixed point method.

\section{Results in RN spaces via Fixed Point Method}

Lemma 2.1. Let $X$ and $Y$ be real vector spaces. A function $f: X \rightarrow Y$ with $f(0)=0$ satisfies (1.7) if and only if $f: X \rightarrow Y$ is additive.

Proof. Let $f$ satisfy the functional equation (1.7). Hence, according to (1.7), we get

$$
\begin{aligned}
& \sum_{i_{1}=2}^{2} \sum_{i_{2}=i_{1}+1}^{3} \ldots \sum_{i_{m-1}=i_{m-2}+1}^{m} f\left(\sum_{i=1, i \neq i_{1}, \ldots, i_{m-1}}^{m} x_{i}-\sum_{r=1}^{m-1} x_{i_{r}}\right) \\
& \quad+\sum_{i_{1}=2}^{3} \sum_{i_{2}=i_{1}+1}^{4} \ldots \sum_{i_{m-2}=i_{m-3}+1}^{m} f\left(\sum_{i=1, i \neq i_{1}, \ldots, i_{m-2}}^{m} x_{i}-\sum_{r=1}^{m-2} x_{i_{r}}\right)+\cdots+\sum_{i_{1}=2}^{m} f\left(\sum_{i=1, i \neq i_{1}}^{m} x_{i}-x_{i_{1}}\right) \\
& \quad+f\left(\sum_{i=1}^{m} x_{i}\right)=2^{m-1} f\left(x_{1}\right)
\end{aligned}
$$


for all $x_{1}, \ldots, x_{m} \in X$. Setting $x_{i}=0(i=2, \ldots, m-1)$ in (2.1), we have

$$
\begin{aligned}
& f\left(x_{1}-x_{m}\right)+\left(\left(\begin{array}{c}
m-2 \\
1
\end{array}\right) f\left(x_{1}-x_{m}\right)+\left(\begin{array}{c}
m-2 \\
m-2
\end{array}\right) f\left(x_{1}+x_{m}\right)\right) \\
& \quad+\cdots+\left(\left(\begin{array}{c}
m-2 \\
m-3
\end{array}\right) f\left(x_{1}-x_{m}\right)+\left(\begin{array}{c}
m-2 \\
2
\end{array}\right) f\left(x_{1}+x_{m}\right)\right) \\
& \quad+\left(\left(\begin{array}{c}
m-2 \\
m-2
\end{array}\right) f\left(x_{1}-x_{m}\right)+\left(\begin{array}{c}
m-2 \\
1
\end{array}\right) f\left(x_{1}+x_{m}\right)\right)+f\left(x_{1}+x_{m}\right)=2^{m-1} f\left(x_{1}\right),
\end{aligned}
$$

that is,

$$
\left(1+\sum_{\ell=1}^{m-2}\left(\begin{array}{c}
m-2 \\
\ell
\end{array}\right)\right)\left(f\left(x_{1}+x_{m}\right)+f\left(x_{1}-x_{m}\right)\right)=2^{m-1} f\left(x_{1}\right)
$$

for all $x_{1}, x_{m} \in X$. On the other hand, we have the relation

$$
1+\sum_{\ell=1}^{m-j}\left(\begin{array}{c}
m-j \\
\ell
\end{array}\right)=\sum_{\ell=0}^{m-j}\left(\begin{array}{c}
m-j \\
\ell
\end{array}\right)=2^{m-j}
$$

for all $m>J$. Hence, we obtain from (2.3) and (2.4) that

$$
f\left(x_{1}+x_{m}\right)+f\left(x_{1}-x_{m}\right)=2 f\left(x_{1}\right)
$$

for all $x_{1}, x_{m} \in X$. Setting $x_{m}=x_{1}$ in (2.5) we get $f\left(2 x_{1}\right)=2 f\left(x_{1}\right)$ for all $x_{1} \in X$. Replacing $x_{1}$ and $x_{m}$ by $x_{1}+x_{m}$ and $x_{1}-x_{m}$ in (2.5), respectively, and then using $f\left(2 x_{1}\right)=2 f\left(x_{1}\right)$, we obtain that

$$
f\left(x_{1}+x_{m}\right)=f\left(x_{1}\right)+f\left(x_{m}\right)
$$

for all $x_{1}, x_{m} \in X$, which implies that $f$ is additive.

Conversely, suppose that $f$ is additive, and thus $f$ satisfies the equation $f\left(x_{1}+x_{2}\right)=$ $f\left(x_{1}\right)+f\left(x_{2}\right)$. Hence we have $f(0)=0$ and $f\left(2 x_{1}\right)=2 f\left(x_{1}\right)$ for all $x_{1} \in X$. Replacing $x_{1}$ and $x_{2}$ by $x_{1}+x_{2}$ and $x_{1}-x_{2}$ in the additive equation and then using $f\left(2 x_{1}\right)=2 f\left(x_{1}\right)$ lead to

$$
f\left(x_{1}+x_{2}\right)+f\left(x_{1}-x_{2}\right)=2 f\left(x_{1}\right)
$$

for all $x_{1}, x_{2} \in X$.

Now, we are going to prove our assumption by induction on $m \geq 2$. It holds for $m=2$; see (2.7). Assume that (1.7) holds for the case, where $m=p$; that is, we have

$$
\sum_{k=2}^{p}\left(\sum_{i_{1}=2}^{k} \sum_{i_{2}=i_{1}+1}^{k+1} \ldots \sum_{i_{p-k+1}=i_{p-k}+1}^{p}\right) f\left(\sum_{i=1, i \neq i_{1}, \ldots, i_{p-k+1}}^{p} x_{i}-\sum_{r=1}^{p-k+1} x_{i_{r}}\right)+f\left(\sum_{i=1}^{p} x_{i}\right)=2^{p-1} f\left(x_{1}\right)
$$


for all $x_{1}, \ldots, x_{p} \in X$. Replacing $x_{1}$ by $x_{1}+x_{p+1}$ in (2.8), we obtain

$$
\begin{aligned}
& \sum_{k=2}^{p}\left(\sum_{i_{1}=2}^{k} \sum_{i_{2}=i_{1}+1}^{k+1} \ldots \sum_{i_{p-k+1}=i_{p-k}+1}^{p}\right) f\left(x_{1}+x_{p+1}+\sum_{i=2, i \neq i_{1}, \ldots, i_{p-k+1}}^{p} x_{i}-\sum_{r=1}^{p-k+1} x_{i_{r}}\right) \\
& \quad+f\left(\sum_{i=1}^{p+1} x_{i}\right)=2^{p-1} f\left(x_{1}+x_{p+1}\right)
\end{aligned}
$$

for all $x_{1}, \ldots, x_{p} \in X$. Replacing $x_{p+1}$ by $-x_{p+1}$ in (2.9), we obtain

$$
\begin{aligned}
& \sum_{k=2}^{p}\left(\sum_{i_{1}=2}^{k} \sum_{i_{2}=i_{1}+1}^{k+1} \ldots \sum_{i_{p-k+1}=i_{p-k}+1}^{p}\right) f\left(x_{1}-x_{p+1}+\sum_{i=2, i \neq i_{1}, \ldots, i_{p-k+1}}^{p} x_{i}-\sum_{r=1}^{p-k+1} x_{i_{r}}\right) \\
& \quad+f\left(\sum_{i=1}^{p} x_{i}-x_{p+1}\right)=2^{p-1} f\left(x_{1}-x_{p+1}\right)
\end{aligned}
$$

for all $x_{1}, \ldots, x_{p+1} \in X$. Adding (2.9) to (2.10), one gets

$$
\begin{aligned}
& \sum_{k=2}^{p+1}\left(\sum_{i_{1}=2}^{k} \sum_{i_{2}=i_{1}+1}^{k+1} \ldots \sum_{i_{p-k+2}=i_{p-k+1}+1}^{p+1}\right) f\left(\sum_{i=1, i \neq i_{1}, \ldots, i_{p-k+2}}^{p+1} x_{i}-\sum_{r=1}^{p-k+2} x_{i_{r}}\right)+f\left(\sum_{i=1}^{p+1} x_{i}\right) \\
& =2^{p-1}\left(f\left(x_{1}+x_{p+1}\right)+f\left(x_{1}-x_{p+1}\right)\right)
\end{aligned}
$$

for all $x_{1}, \ldots, x_{p+1} \in X$. Therefore, it follows from (2.7) and (2.11) that (1.7) holds for $m=p+1$. This completes the proof of the theorem.

From now on, let $X$ be a linear space and $\left(Y, \Lambda, T_{M}\right)$ a complete $R N$ space. For convenience, we use the following abbreviation for a given function $f: X \rightarrow Y$ :

$$
\begin{aligned}
D_{f}\left(x_{1}, \ldots, x_{m}\right)= & \sum_{k=2}^{m}\left(\sum_{i_{1}=2}^{k} \sum_{i_{2}=i_{1}+1}^{k+1} \ldots \sum_{i_{m-k+1}=i_{m-k}+1}^{m}\right) f\left(\sum_{i=1, i \neq i_{1}, \ldots, i_{m-k+1}}^{m} x_{i}-\sum_{r=1}^{m-k+1} x_{i_{r}}\right) \\
& +f\left(\sum_{i=1}^{m} x_{i}\right)-2^{m-1} f\left(x_{1}\right)
\end{aligned}
$$

for all $x_{1}, \ldots, x_{m} \in X$, where $m \geq 2$ is an integer number.

Theorem 2.2. Let $\Phi: \underbrace{X \times X \times \cdots \times X}_{m \text {-terms }} \rightarrow D^{+}$be a function $\left(\Phi\left(x_{1}, \ldots, x_{m}\right)\right.$ is denoted by $\left.\Phi_{x_{1}, \ldots, x_{m}}\right)$ such that, for some $0<\alpha<2$,

$$
\Phi_{2 x_{1}, \ldots, 2 x_{m}}(\alpha t) \geq \Phi_{x_{1, \ldots, x_{m}}}(t)
$$


for all $x_{1}, \ldots, x_{m} \in X$ and all $t>0$. Suppose that a function $f: X \rightarrow Y$ with $f(0)=0$ satisfies the inequality

$$
\Lambda_{D_{f}\left(x_{1}, \ldots, x_{m}\right)}(t) \geq \Phi_{x_{1}, \ldots, x_{m}}(t)
$$

for all $x_{1}, \ldots, x_{m} \in X$ and all $t>0$. Then, there exists a unique additive function $A: X \rightarrow Y$ such that

$$
\Lambda_{f(x)-A(x)}(t) \geq \Phi_{x, x, \underbrace{0, \ldots, 0}_{m-2}}\left(2^{m-2}(2-\alpha) t\right)
$$

for all $x \in X$ and all $t>0$.

Proof. Letting $x_{i}=0(i=3, \ldots, m)$ in $(2.14)$, we get

$$
\Lambda_{\left(1+\sum_{\ell=1}^{m-2}\left(\begin{array}{c}
m-2 \\
\ell
\end{array}\right)\right)\left(f\left(x_{1}+x_{2}\right)+f\left(x_{1}-x_{2}\right)\right)-2^{m-1} f\left(x_{1}\right)}(t) \geq \Phi_{x_{1}, x_{2}, 0, \ldots, 0}(t)
$$

for all $x_{1}, x_{2} \in X$ and all $t>0$. Setting $x_{1}=x_{2}=x$ in (2.16), we obtain from (2.4) and $f(0)=0$ that

$$
\Lambda_{2^{m-2} f(2 x)-2^{m-1} f(x)}(t) \geq \Phi_{x, x, 0, \ldots, 0}(t)
$$

for all $x \in X$ and all $t>0$, or

$$
\Lambda_{f(2 x) / 2-f(x)}(t) \geq \Phi_{x, x, 0, \ldots, 0}\left(2^{m-1} t\right)
$$

for all $x \in X$ and all $t>0$. Let $S$ be the set of all functions $h: X \rightarrow Y$ with $h(0)=0$ and introduce a generalized metric on $S$ as follows:

$$
d(h, k)=\inf \left\{u \in \mathbb{R}^{+}: \Lambda_{h(x)-k(x)}(u t) \geq \Phi_{x, x, 0, \ldots, 0}(t), \forall x \in X, \forall t>0\right\},
$$

where, as usual, $\inf \emptyset=+\infty$. It is easy to show that $(S, d)$ is a generalized complete metric space $[26,45]$.

Now we consider the function $J: S \rightarrow S$ defined by

$$
J h(x):=\frac{h(2 x)}{2}
$$

for all $h \in S$ and $x \in X$.

Now let $g, f \in S$ such that $d(f, g)<\varepsilon$. Then,

$$
\Lambda_{J g(x)-J f(x)}\left(\frac{\alpha \varepsilon}{2} t\right)=\Lambda_{g(2 x)-f(2 x)}(\alpha \varepsilon t) \geq \Phi_{2 x, 2 x, 0, \ldots, 0}(\alpha t) \geq \Phi_{x, x, 0, \ldots, 0}(t),
$$


that is, if $d(f, g)<\varepsilon$, we have $d(J f, J g)<(\alpha / 2) \varepsilon$. This means that

$$
d(J f, J g) \leq \frac{\alpha}{2} d(f, g)
$$

for all $f, g \in S$, that is, $J$ is a strictly contractive self-function on $S$ with the Lipschitz constant $\alpha / 2$.

It follows from (2.18) that

$$
\Lambda_{J f(x)-f(x)}\left(\frac{t}{2^{m-1}}\right) \geq \Phi_{x, x, 0, \ldots, 0}(t)
$$

for all $x \in X$ and all $t>0$, which implies that $d(J f, f) \leq 1 / 2^{m-1}$.

Due to Theorem 1.5, there exists a function $A: X \rightarrow Y$ such that $A$ is a fixed point of $J$, that is, $A(2 x)=2 A(x)$ for all $x \in X$.

Also, $d\left(J^{n} f, A\right) \rightarrow 0$ as $n \rightarrow \infty$, implies the equality

$$
\lim _{n \rightarrow \infty} \frac{f\left(2^{n} x\right)}{2^{n}}=A(x)
$$

for all $x \in X$. If we replace $x_{1}, \ldots, x_{m}$ with $2^{n} x_{1}, \ldots, 2^{n} x_{m}$ in (2.14), respectively, and divide by $2^{n}$, then it follows from (2.13) that

$$
\Lambda_{D_{f}\left(2^{n} x_{1}, \ldots, 2^{n} x_{m}\right) / 2^{n}}(t) \geq \Phi_{2^{n} x_{1}, \ldots, 2^{n} x_{m}}\left(2^{n} t\right)=\Phi_{2^{n} x_{1}, \ldots, 2^{n} x_{m}}\left(\alpha^{n}\left(\frac{2}{\alpha}\right)^{n} t\right) \geq \Phi_{x_{1}, \ldots, x_{m}}\left(\left(\frac{2}{\alpha}\right)^{n} t\right)
$$

for all $x_{1}, \ldots, x_{m} \in X$ and all $t>0$. By letting $n \rightarrow \infty$ in (2.25), we find that $\Lambda_{D_{A}\left(x_{1}, \ldots, x_{m}\right)}(t)=1$ for all $t>0$, which implies $D_{A}\left(x_{1}, \ldots, x_{m}\right)=0$, and thus $A$ satisfies (1.7). Hence by Lemma 2.1, the function $A: X \rightarrow Y$ is additive.

According to the fixed point alterative, since $A$ is the unique fixed point of $J$ in the set $\Omega=\{g \in S: d(f, g)<\infty\}, A$ is the unique function such that

$$
\Lambda_{f(x)-A(x)}(u t) \geq \Phi_{x, x, 0, \ldots, 0}(t)
$$

for all $x \in X$ and all $t>0$. Again using the fixed point alterative gives

$$
d(f, A) \leq \frac{1}{1-L} d(f, J f) \leq \frac{1}{2^{m-1}(1-L)}=\frac{1}{2^{m-1}(1-\alpha / 2)}
$$

which implies the inequality

$$
\Lambda_{f(x)-A(x)}\left(\frac{t}{2^{m-2}(2-\alpha)}\right) \geq \Phi_{x, x, 0, \ldots, 0}(t)
$$


for all $x \in X$ and all $t>0$. So,

$$
\Lambda_{f(x)-A(x)}(t) \geq \Phi_{x, x, 0, \ldots, 0}\left(2^{m-2}(2-\alpha) t\right)
$$

for all $x \in X$ and all $t>0$. This completes the proof.

Now, we present a corollary that is an application of the last theorem in the classical case.

Corollary 2.3. Let $(X,\|\cdot\|)$ and $(Y,\|\cdot\|)$, normed linear spaces, define

$$
\Lambda_{x}(t)=\frac{t}{t+\|x\|}
$$

for $x \in X$ and $t>0$. Define

$$
\Phi_{x_{1}, \ldots, x_{m}}(t)=\frac{t}{t+\sum_{i=1}^{m}\left\|x_{i}\right\|^{p}}
$$

for all $x_{1}, \ldots, x_{m} \in X$ and all $t>0$ in which $p<1$. Now, for $\alpha=2^{p},(2.13)$ holds for all $x_{1}, \ldots, x_{m} \in$ $X$ and all $t>0$. Suppose that an odd function $f: X \rightarrow Y$ satisfies (2.14) for all $x_{1}, \ldots, x_{n} \in X$ and all $t>0$. Then, by the last theorem there exists a unique additive function $A: X \rightarrow Y$ such that

$$
\frac{t}{t+\|f(x)-A(x)\|} \geq \frac{t}{t+1 / 2^{m-2}\left(1-2^{p-1}\right)\|x\|^{p}}
$$

for all $x \in X$ and all $t>0$. Hence,

$$
\|f(x)-A(x)\| \leq \frac{1}{2^{m-2}\left(1-2^{p-1}\right)}\|x\|^{p}
$$

for all $x \in X$.

Theorem 2.4. Let $\Phi: \underbrace{X \times X \times \cdots \times X}_{m \text {-terms }} \rightarrow D^{+}$be a function such that, for some $0<\alpha<3$,

$$
\Phi_{3 x_{1}, \ldots, 3 x_{m}}(\alpha t) \geq \Phi_{x_{1}, \ldots, x_{m}}(t)
$$

for all $x_{1}, \ldots, x_{m} \in X$ and all $t>0$. Suppose that an odd function $f: X \rightarrow Y$ satisfies (2.14) for all $x_{1}, \ldots, x_{n} \in X$ and all $t>0$. Then, there exists a unique additive function $A: X \rightarrow Y$ such that

$$
\Lambda_{f(x)-A(x)}(t) \geq \Phi_{x, x, x,} \underbrace{0, \ldots, 0}_{m-3}\left(2^{m-3}(3-\alpha) t\right)
$$

for all $x \in X$ and all $t>0$. 
Proof. Letting $x_{i}=0(i=4, \ldots, m)$ in (2.14), we get

$$
\Lambda_{\left(1+\sum_{\ell=1}^{m-3}\left(\begin{array}{c}
n-3 \\
\ell
\end{array}\right)\right)\left(f\left(x_{1}+x_{2}+x_{3}\right)+f\left(x_{1}-x_{2}+x_{3}\right)+f\left(x_{1}+x_{2}-x_{3}\right)+f\left(x_{1}-x_{2}-x_{3}\right)\right)-2^{m-1} f\left(x_{1}\right)}(t) \geq \Phi_{x_{1}, x_{2}, x_{3}, 0, \ldots, 0}(t)
$$

for all $x_{1}, x_{2}, x_{3} \in X$ and all $t>0$. Setting $x_{1}=x_{2}=x_{3}=x$ in the last inequality, we obtain by using oddness of $f$ and (2.4) that

$$
\Lambda_{2^{m-3} f(3 x)+f(x)-2^{m-1} f(x)}(t) \geq \Phi_{x, x, x, 0, \ldots, 0}(t)
$$

for all $x \in X$ and all $t>0$, or

$$
\Lambda_{(f(3 x) / 3)-f(x)}(t) \geq \Phi_{x, x, x, 0, \ldots, 0}\left(3.2^{m-3} t\right)
$$

for all $x \in X$ and all $t>0$. Let $S$ be the set of all odd functions $h: X \rightarrow Y$, and introduce a generalized metric on $S$ as follows:

$$
d(h, k)=\inf \left\{u \in \mathbb{R}^{+}: \Lambda_{h(x)-k(x)}(u t) \geq \Phi_{x, x, x, 0, \ldots, 0}(t), \forall x \in X, \forall t>0\right\}
$$

It is easy to show that $(S, d)$ is a generalized complete metric space [26, 45]. Let $J: S \rightarrow S$ be the function defined by

$$
J h(x):=\frac{h(3 x)}{3}
$$

for all $h \in S$ and $x \in X$. One can show that

$$
d(J f, J g) \leq \frac{\alpha}{3} d(f, g)
$$

for all $f, g \in S$, that is, $J$ is a strictly contractive self-function on $S$ with the Lipschitz constant $\alpha / 3$.

It follows from (2.38) that

$$
\Lambda_{J f(x)-f(x)}\left(\frac{t}{3.2^{m-3}}\right) \geq \Phi_{x, x, x, 0, \ldots, 0}(t)
$$

for all $x \in X$ and all $t>0$, which implies that $d(J f, f) \leq\left(1 / 3.2^{m-3}\right)$.

Due to Theorem 1.5, the sequence $\left\{J^{n}\right\}$ converges to a fixed point $A$ of $J$, that is,

$$
A: X \longrightarrow Y, \quad A(x)=\lim _{n \rightarrow \infty} J^{n} f(x)=\lim _{n \rightarrow \infty} \frac{f\left(3^{n} x\right)}{3^{n}}
$$

and $A(3 x)=3 A(x)$ for all $x \in X$. 
Discrete Dynamics in Nature and Society

Also, $A$ is the unique fixed point of $J$ in the set $\Omega=\{g \in S: d(f, g)<\infty\}$, and

$$
d(f, A) \leq \frac{1}{1-L} d(f, J f) \leq \frac{1}{3.2^{m-3}(1-L)}=\frac{1}{3.2^{m-3}(1-\alpha / 3)}
$$

implies the inequality

$$
\Lambda_{f(x)-A(x)}\left(\frac{t}{2^{m-3}(3-\alpha)}\right) \geq \Phi_{x, x, x, 0, \ldots, 0}(t)
$$

for all $x \in X$ and all $t>0$. This implies that inequality (2.35) holds. Furthermore, we can obtain that the function $A: X \rightarrow Y$ satisfies (1.7). Hence by Lemma 2.1, we get that the function $A: X \rightarrow Y$ is additive.

Now, we present a corollary that is an application of the last theorem in the classical case.

Corollary 2.5. Let $(X,\|\cdot\|)$ and $(Y,\|\cdot\|)$, normed linear spaces, define

$$
\Lambda_{x}(t)=\frac{t}{t+\|x\|}
$$

for $x \in X$ and $t>0$. Define

$$
\Phi_{x_{1}, \ldots, x_{m}}(t)=\frac{t}{t+\sum_{i=1}^{m}\left\|x_{i}\right\|^{p}}
$$

for all $x_{1}, \ldots, x_{m} \in X$ and all $t>0$ in which $p<1$. Now, for $\alpha=3^{p},(2.34)$ holds for all $x_{1}, \ldots, x_{m} \in$ $X$ and all $t>0$. Suppose that an odd function $f: X \rightarrow Y$ satisfies (2.14) for all $x_{1}, \ldots, x_{n} \in X$ and all $t>0$. Then, by the last theorem there exists a unique additive function $A: X \rightarrow Y$ such that

$$
\frac{t}{t+\|f(x)-A(x)\|} \geq \frac{t}{t+1 / 2^{m-3}\left(1-3^{p-1}\right)\|x\|^{p}}
$$

for all $x \in X$ and all $t>0$. Hence,

$$
\|f(x)-A(x)\| \leq \frac{1}{2^{m-3}\left(1-3^{p-1}\right)}\|x\|^{p}
$$

for all $x \in X$.

\section{Acknowledgments}

The authors would like to thank the referees and the Editor Professor Seenith Sivasundaram for giving useful suggestions for the improvement of this paper. 


\section{References}

[1] S. M. Ulam, A Collection of Mathematical Problems, Interscience Publishers, London, UK, 1960.

[2] D. H. Hyers, "On the stability of the linear functional equation," Proceedings of the National Academy of Sciences of the United States of America, vol. 27, pp. 222-224, 1941.

[3] T. Aoki, "On the stability of the linear transformation in Banach spaces," Journal of the Mathematical Society of Japan, vol. 2, pp. 64-66, 1950.

[4] T. M. Rassias, "On the stability of the linear mapping in Banach spaces," Proceedings of the American Mathematical Society, vol. 72, no. 2, pp. 297-300, 1978.

[5] P. Găvruţa, "A generalization of the Hyers-Ulam-Rassias stability of approximately additive mappings," Journal of Mathematical Analysis and Applications, vol. 184, no. 3, pp. 431-436, 1994.

[6] P. W. Cholewa, "Remarks on the stability of functional equations," Aequationes Mathematicae, vol. 27, no. 1-2, pp. 76-86, 1984.

[7] M. Eshaghi Gordji and H. Khodaei, "Solution and stability of generalized mixed type cubic, quadratic and additive functional equation in quasi-Banach spaces," Nonlinear Analysis. Theory, Methods $\mathcal{E}$ Applications, vol. 71, no. 11, pp. 5629-5643, 2009.

[8] M. Eshaghi Gordji and H. Khodaei, "On the generalized Hyers-Ulam-Rassias stability of quadratic functional equations," Abstract and Applied Analysis, vol. 2009, Article ID 923476, 11 pages, 2009.

[9] C. Park, M. E. Gordji, and H. Khodaei, "A fixed point approach to the Cauchy-Rassias stability of general Jensen type quadratic-quadratic mappings," Bulletin of the Korean Mathematical Society, vol. 47, no. 5, pp. 987-996, 2010.

[10] Z. Gajda, "On stability of additive mappings," International Journal of Mathematics and Mathematical Sciences, vol. 14, no. 3, pp. 431-434, 1991.

[11] D. H. Hyers, G. Isac, and T. M. Rassias, Stability of Functional Equations in Several Variables, Birkhäuser Boston, Boston, Mass, USA, 1998.

[12] G. Isac and T. M. Rassias, "Stability of $\psi$-additive mappings: applications to nonlinear analysis," International Journal of Mathematics and Mathematical Sciences, vol. 19, no. 2, pp. 219-228, 1996.

[13] S.-M. Jung, Hyers-Ulam-Rassias Stability of Functional Equations in Mathematical Analysis, Hadronic, Palm Harbor, Fla, USA, 2001.

[14] C. Park, "Fixed points and Hyers-Ulam-Rassias stability of Cauchy-Jensen functional equations in Banach algebras," Fixed Point Theory and Applications, vol. 2007, Article ID 50175, 15 pages, 2007.

[15] C. Park, "Hyers-Ulam-Rassias stability of a generalized Apollonius-Jensen type additive mapping and isomorphisms between $C^{*}$-algebras," Mathematische Nachrichten, vol. 281, no. 3, pp. 402-411, 2008.

[16] V. Radu, "The fixed point alternative and the stability of functional equations," Fixed Point Theory, vol. 4, no. 1, pp. 91-96, 2003.

[17] T. M. Rassias, "Problem 16; 2, Report of the 27th International Symposium on Functional Equations," Aequationes mathematicae, vol. 39, article 309, pp. 292-293, 1990.

[18] T. M. Rassias, "On the stability of the quadratic functional equation and its applications," Universitatis Babeş-Bolyai. Studia. Mathematica, vol. 43, no. 3, pp. 89-124, 1998.

[19] T. M. Rassias, "The problem of S. M. Ulam for approximately multiplicative mappings," Journal of Mathematical Analysis and Applications, vol. 246, no. 2, pp. 352-378, 2000.

[20] T. M. Rassias, "On the stability of functional equations in Banach spaces," Journal of Mathematical Analysis and Applications, vol. 251, no. 1, pp. 264-284, 2000.

[21] T. M. Rassias, "On the stability of functional equations and a problem of Ulam," Acta Applicandae Mathematicae, vol. 62, no. 1, pp. 23-130, 2000.

[22] T. M. Rassias and P. Šemrl, "On the behavior of mappings which do not satisfy Hyers-Ulam stability," Proceedings of the American Mathematical Society, vol. 114, no. 4, pp. 989-993, 1992.

[23] T. M. Rassias and P. Šemrl, "On the Hyers-Ulam stability of linear mappings," Journal of Mathematical Analysis and Applications, vol. 173, no. 2, pp. 325-338, 1993.

[24] T. M. Rassias and K. Shibata, "Variational problem of some quadratic functionals in complex analysis," Journal of Mathematical Analysis and Applications, vol. 228, no. 1, pp. 234-253, 1998.

[25] S.-S. Chang, Y. J. Cho, and S. M. Kang, Nonlinear Operator Theory in Probabilistic Metric Spaces, Nova Science, Huntington, NY, USA, 2001.

[26] D. Miheț and V. Radu, "On the stability of the additive Cauchy functional equation in random normed spaces," Journal of Mathematical Analysis and Applications, vol. 343, no. 1, pp. 567-572, 2008.

[27] D. Miheț, "The stability of the additive Cauchy functional equation in non-Archimedean fuzzy normed spaces," Fuzzy Sets and Systems, vol. 161, no. 16, pp. 2206-2212, 2010 (English).

[28] B. Schweizer and A. Sklar, Probabilistic Metric Spaces, North-Holland, New York, NY, USA, 1983. 
[29] A. N. Šerstnev, “On the concept of a stochastic normalized space," Doklady Akademii Nauk SSSR, vol. 149 , pp. 280-283, 1963 (Russian).

[30] O. Hadžić and E. Pap, Fixed Point Theory in Probabilistic Metric Spaces, vol. 536, Kluwer Academic Publishers, Dordrecht, The Netherlands, 2001.

[31] O. Hadžić, E. Pap, and M. Budinčević, "Countable extension of triangular norms and their applications to the fixed point theory in probabilistic metric spaces," Kybernetika, vol. 38, no. 3, pp. 363-382, 2002.

[32] L. Cădariu and V. Radu, "Fixed points and the stability of Jensen's functional equation," Journal of Inequalities in Pure and Applied Mathematics, vol. 4, no. 1, article 4, p. 7, 2003.

[33] J. B. Diaz and B. Margolis, "A fixed point theorem of the alternative, for contractions on a generalized complete metric space," Bulletin of the American Mathematical Society, vol. 74, pp. 305-309, 1968.

[34] C. Alsina, "On the stability of a functional equation arising in probabilistic normed spaces," in General Inequalities, vol. 80, pp. 263-271, Birkhäuser, Basel, Switzerland, 1987.

[35] M. Mirzavaziri and M. S. Moslehian, "A fixed point approach to stability of a quadratic equation," Bulletin of the Brazilian Mathematical Society, vol. 37, no. 3, pp. 361-376, 2006.

[36] A. K. Mirmostafaee and M. S. Moslehian, "Fuzzy approximately cubic mappings," Information Sciences, vol. 178, no. 19, pp. 3791-3798, 2008.

[37] A. K. Mirmostafaee, M. Mirzavaziri, and M. S. Moslehian, "Fuzzy stability of the Jensen functional equation," Fuzzy Sets and Systems, vol. 159, no. 6, pp. 730-738, 2008.

[38] A. K. Mirmostafaee and M. S. Moslehian, "Fuzzy versions of Hyers-Ulam-Rassias theorem," Fuzzy Sets and Systems, vol. 159, no. 6, pp. 720-729, 2008.

[39] D. Miheţ, "The probabilistic stability for a functional equation in a single variable," Acta Mathematica Hungarica, vol. 123, no. 3, pp. 249-256, 2009.

[40] D. Miheț, "The fixed point method for fuzzy stability of the Jensen functional equation," Fuzzy Sets and Systems, vol. 160, no. 11, pp. 1663-1667, 2009.

[41] D. Miheț, R. Saadati, and S. M. Vaezpour, "The stability of the quartic functional equation in random normed spaces," Acta Applicandae Mathematicae, vol. 110, no. 2, pp. 797-803, 2010.

[42] D. Miheţ, R. Saadati, and S. M. Vaezpour, "The stability of an additive functional equation in Menger probabilistic $\phi$-normed spaces," Mathematica Slovaca, vol. 61, no. 5, pp. 817-826, 2011.

[43] E. Baktash, Y. J. Cho, M. Jalili, R. Saadati, and S. M. Vaezpour, "On the stability of cubic mappings and quadratic mappings in random normed spaces," Journal of Inequalities and Applications, vol. 2008, Article ID 902187, 11 pages, 2008.

[44] R. Saadati, S. M. Vaezpour, and Y. J. Cho, "A note to paper "On the stability of cubic mappings and quartic mappings in random normed spaces"," Journal of Inequalities and Applications, vol. 2009, Article ID 214530, 6 pages, 2009.

[45] L. Cădariu and V. Radu, "On the stability of the Cauchy functional equation: a fixed point approach," in Iteration Theory, vol. 346, pp. 43-52, Karl-Franzens-Universitaet Graz, Graz, Austria, 2004. 


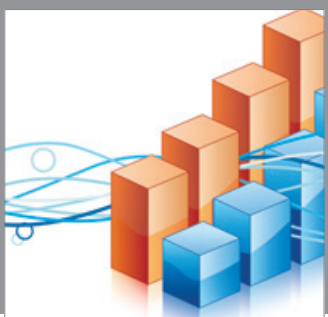

Advances in

Operations Research

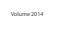

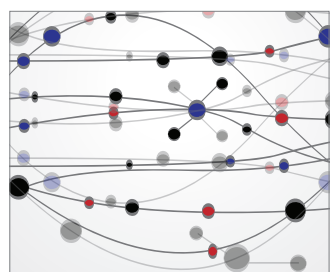

\section{The Scientific} World Journal
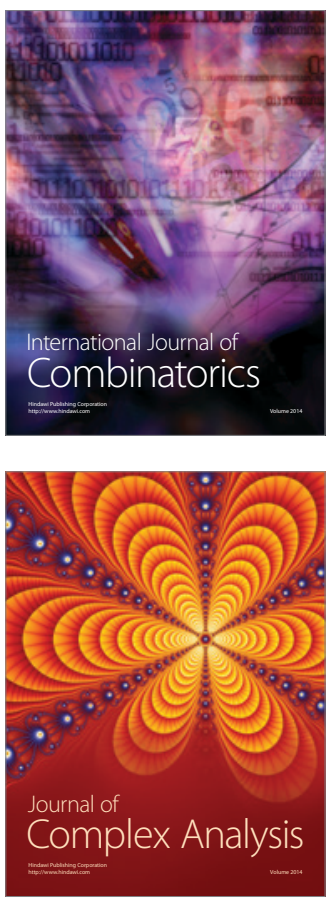

International Journal of

Mathematics and

Mathematical

Sciences
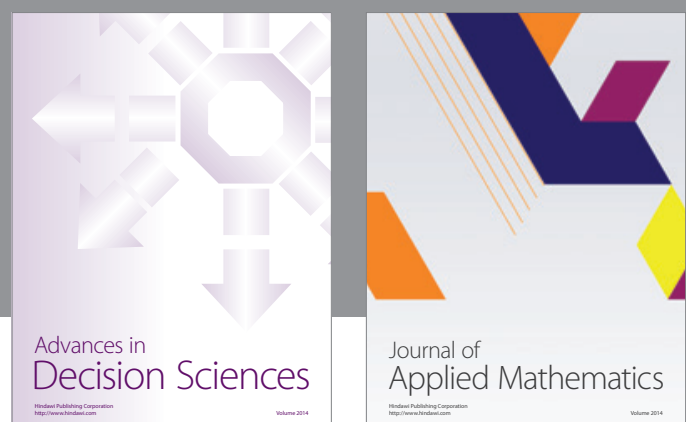

Journal of

Applied Mathematics
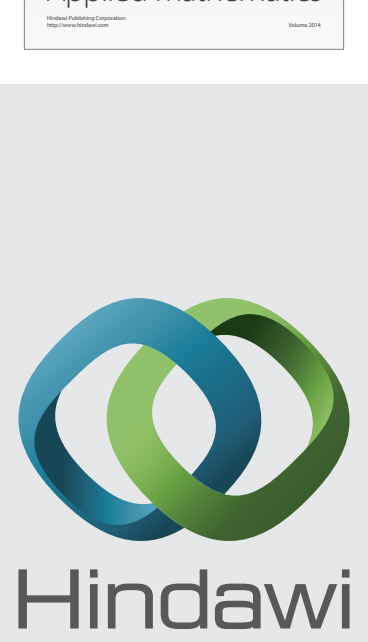

Submit your manuscripts at http://www.hindawi.com
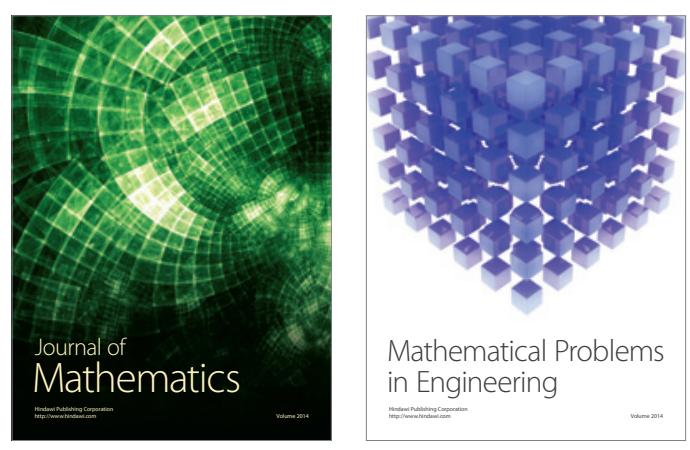

Mathematical Problems in Engineering
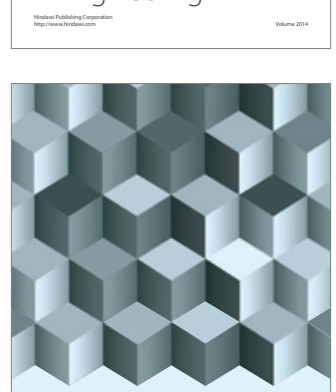

Journal of

Function Spaces
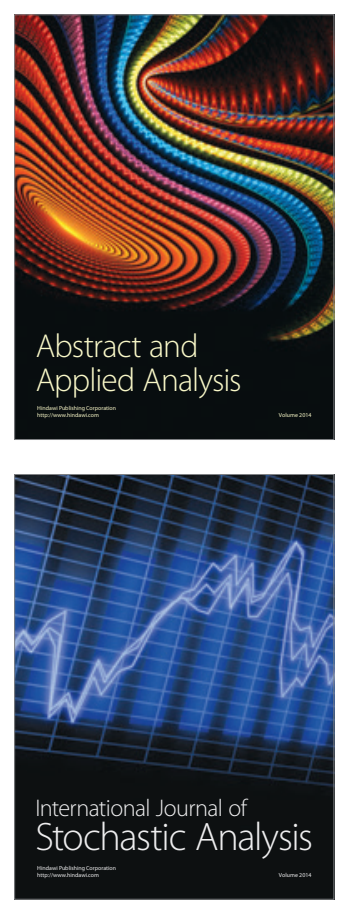

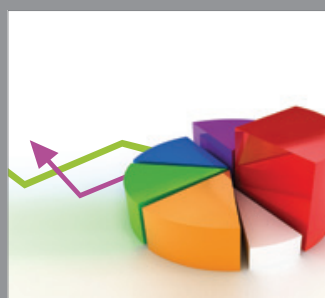

ournal of

Probability and Statistics

Promensencen
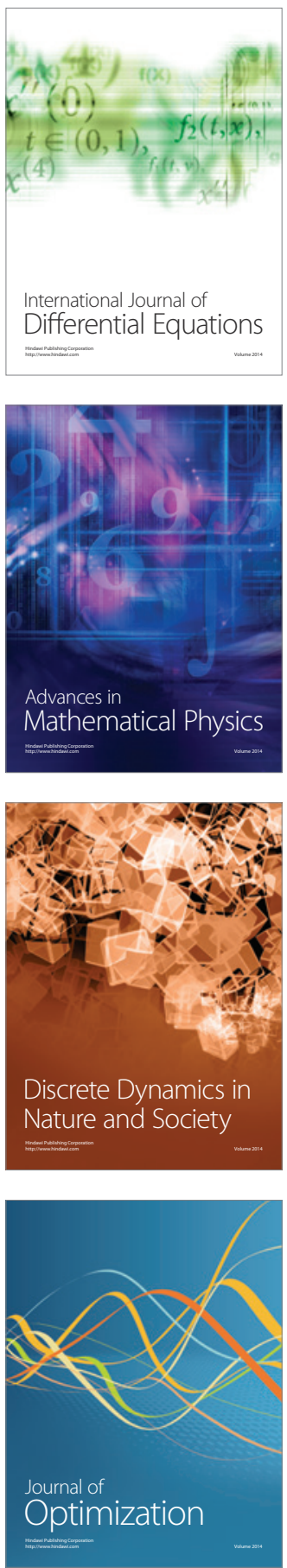